\title{
LETRAMENTO(S): CONCEITOS DE TRABALHO NO ENSINO ${ }^{1}$
}

\section{LITERACY(IES): WORKING CONCEPTS IN TEACHING}

\author{
Manoel Luiz Gonçalves Corrêa \\ Universidade de São Paulo, São Paulo, São Paulo, Brasil
}

\begin{abstract}
Resumo: Em Courtine e Vigarello (2009), são tematizados os modos, tecnologicamente informados, de tipificar o corpo do imputável a partir do século XIX. Desse processo, destaco o seu final, em que o efeito dessa tipificação culmina no controle dos corpos. Contrapondo vacuidade e densidade dos corpos, este trabalho assume como tarefa a indagação sobre como, na escola, se dá a descorporificação dos conceitos (conteúdos curriculares) e sobre como evitá-la. De uma perspectiva discursiva em Linguística Aplicada, a reflexão central introduz, ao tratar do(s) letramento(s), a noção de conceito de trabalho (STREET, 2009) para estabelecer o diálogo entre o objeto de ensino, o professor e o aluno, diálogo, portanto, entre os três participantes fundamentais da prática didático-pedagógica. A novidade em relação à noção de conceito de trabalho é a sua proposição como o espaço ótimo para se estabelecer um novo modo de produzir conhecimento, em que a transdisciplinaridade (SIGNORINI, 1998) se ocupa menos das disciplinas do que da produção dos objetos de reflexão no acontecimento da relação entre disciplinas.
\end{abstract}

Palavras-chave: Letramento; Conceito de Trabalho; Descorporificação; Ensino; Tecnologia

\begin{abstract}
Courtine and Vigarello (2009) present the technologically informed ways of categorizing the indictable body from the 19th century onwards. I highlight the outcome of this process when the effect of this categorization leads to the control of the bodies. Contrasting the empty body with the full one, this paper assumes the task of asking about how the body of concepts (the syllabus) is drained out at school and how to avoid it. From a discursive perspective in the Applied Linguistics, the main point is to introduce the working concept (STREET, 2009) to deal with literacy(ies), establishing a dialogue between the learning objects, the teacher and the student, that is, a dialogue between the three main participants of the didactic-pedagogic practice. The novelty in relation to the notion of working concept is its proposition as the optimum environment to establish a new way of knowledge production in which transdisciplinarity (SIGNORINI, 1998) is not so concerned with the disciplines, but with the production of reflection issues in the happening of a relation between disciplines.
\end{abstract}

Keywords: Literacy; Working Concept; Disembodiment; Teaching; Technology

\footnotetext{
${ }^{1}$ Agradeço a Arnaldo Franco Junior pela leitura e pelas contribuições.
} 


\section{INTRODUÇÃO}

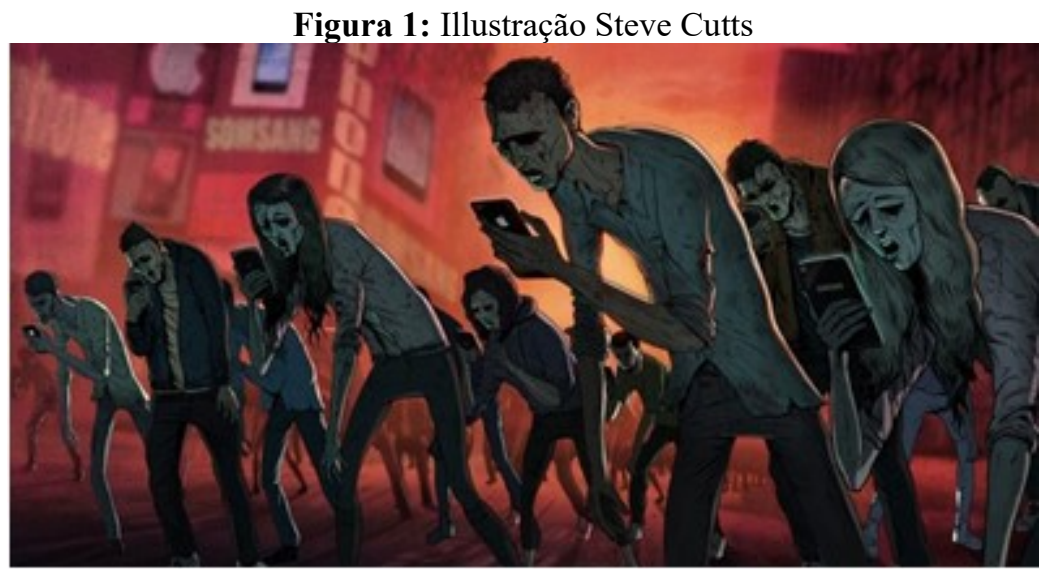

Fonte: Steve Cutts $-<\mathrm{http}: / /$ www.stevecutts.com $/>^{2}$

A imagem utilizada como epígrafe é apenas um dos exemplos da relação entre tecnologia e corpo. No entanto, por ser um viés que ficará em segundo plano neste texto, optei por utilizá-la na epígrafe como forma de não excluí-lo de consideração. Outras situações poderiam ser citadas. Por exemplo, a relação entre os cortes de frango nas gôndolas de supermercado (há uma complexa tecnologia industrial até se chegar aos tipos de corte) e o corpo vivo e ao vivo do animal, desconhecido de muitas crianças. Ou, ainda, o valor superior e o cuidado que muitas pessoas devotam aos carros em detrimento do próprio corpo (valeria a pena avaliar a importância dada ao cuidado com o carro e ao cuidado de si) e ao corpo do outro (p. ex., do transeunte, que parece tornar-se, cada vez mais, um estorvo). Essas situações fazem referência ao corpo como estrutura física do organismo vivo, mas, em todas, há o espectro do cadáver, o corpo sem vida. Em todas, pode-se supor algum aspecto ligado a mortos-vivos, corpos vagos, sem densidade nem direção própria.

O objetivo deste trabalho é mostrar uma situação similar no campo da educação, o que farei na segunda parte do artigo. Adianto, porém, duas entradas para o tema da descorporificação naquele campo: o tema do(s) letramento(s) e os três elementos centrais da prática didático-pedagógica.

Num momento em que, por vias transversas, a obra e a figura de Paulo Freire ${ }^{3}$ se fortalece no cenário intelectual brasileiro, também o conceito de letramento ganha outra dimensão, pelo menos nos limites da nossa história recente. A verdade é que se uma obra ou um conceito se redimensionam num determinado momento histórico, é porque há em ambos algo que permite esse redimensionamento.

No que se refere ao conceito de letramento, é importante lembrar, de início, que ele é inicialmente proposto para cobrir um campo muito mais amplo do que o da alfabetização, pelo menos quando o entendimento a respeito desta última se limita ao estrito domínio do sistema alfabético. Enquanto a alfabetização se liga a um conhecimento formal adquirido na escola ou fora dela, o letramento cobre tanto o campo da educação formal, o da escola, onde $\mathrm{o}(\mathrm{s})$ letramento(s) pode $(\mathrm{m})$ ser diversificado(s) e aprofundado(s); quanto o campo da educação não formal - o de espaços que se situam fora da escola, nos quais o(s) letramento(s) também pode(m) ser diversificado(s) e aprofundado(s) - e, também, o campo da educação

\footnotetext{
${ }^{2}$ Ilustração retirada de CALLIARI, 2017.

${ }^{3}$ Em maio de 2019, a Faculdade de Educação da Unicamp deu o nome de Paulo Freire ao seu prédio principal. Esse ato, que o momento histórico do país permite definir como um ato político, só se constitui como tal em virtude do peso acadêmico do homenageado.
} 
informal em que a circulação dos saberes permite o acesso ao(s) letramento(s) de maneira não planejada formalmente. A própria crítica que Street (1984) faz a Paulo Freire consiste, basicamente, na atenção extremada que o autor atribui ao pensamento de Freire no que se refere à escrita (e à alfabetização) como forma de libertação do indivíduo de condições sociais de exploração. Quer concordemos ou não com ela, essa crítica de Street mostra que a noção de letramento não se limita ao domínio da escrita, nem, tampouco, ao domínio do sistema alfabético. Talvez se pudesse defender que a noção de letramento seja vista até mesmo como um modo particular de interpretar a proposta freiriana, o que parece ser verdadeiro ao menos no que se refere ao trânsito entre educação informal, formal e não formal.

Outro aspecto a respeito da noção de letramento é a própria diversidade do(s) letramento(s) e sua complexa combinação, atestadas não só na sua gênese em diferentes práticas sociais, mas constatadas, também, numa mesma prática, num mesmo sujeito e num mesmo texto. O leque de adjetivações que a palavra "letramento" adquiriu deve, a meu ver, ser pensando como uma tentativa de dar especificidade a um fenômeno que está ligado à constituição dos saberes numa sociedade. Nesse contexto é que considero importante que as práticas que constituem os vários tipos de letramento não sejam, em função de sua especificidade, consideradas isoladas, já que, sendo práticas sociais, estão em permanente contato.

Por outro lado, o(s) letramento(s) não se marcam apenas pelo recurso à escrita, pois as práticas de que eles provêm lançam mão de diferentes semioses para a produção de sentido. Ora, os saberes nelas produzidos são, portanto, marcados pela multimodalidade. Nesse sentido, o(s) letramento(s) estão sujeitos à convivência multimodal da mesma forma que se produzem na relação entre práticas sociais. Há, pois, heterogeneidade nos diferentes tipos de letramento sob qualquer ângulo de sua constituição.

Em suma, interessa reter sobre o(s) letramento(s) que ele(s), tendo ligação direta ou indireta com a escrita, manifestam-se pelo caráter vital da integração dos indivíduos às diferentes práticas sociais de que participam e às suas formas de produção de sentido. A vida que o(s) letramento(s) atestam é, pois, a da integração ativa dos indivíduos à sociedade e à história, aspecto que os distancia dos mortos-vivos anteriormente mencionados. Por isso, desde o surgimento do conceito, restringi-lo à alfabetização corresponde a esvaziá-lo de sentido, a retirar do conceito a sua procedência relacionada aos modos de produção de sentido de uma sociedade, a retirar dele aquilo que lhe dá corpo.

Para cumprir o objetivo anunciado de lidar com situações de corpos vagos - penso em conceitos subtraídos da vida que os constitui - no campo da educação, parto de uma relação específica entre tecnologia e corpo, restringindo-a à história da Medicina Legal tal como descrita e analisada por Courtine e Vigarello no capítulo "Identificar - traços, indícios, suspeitas", publicado no terceiro volume da coleção História do corpo: as mutações do olhar o século XX. Procuro, por meio da relação entre tecnologia e corpo, mostrar como os recursos de identificação do criminoso na Medicina legal produzem o que chamo de corpo controlado, também uma espécie de cadáver que, sem estar decomposto, perde suas qualidades distintivas fundamentais em função de sua instrumentalização por mecanismos de poder, dos quais a burocracia é um representante dos mais importantes. Ao efeito desses mecanismos de poder chamo descorporificação. Uma breve discussão sobre o assunto é feita na primeira parte do trabalho.

$\mathrm{Na}$ segunda parte, a discussão se concentra no campo da educação, ainda que mantendo a atenção na linguagem. A abordagem dos três elementos fundamentais da prática didático-pedagógica é, por exemplo, feita em função dos elementos básicos da comunicação: a referência e os participantes que a co-instauram (o professor e o aluno). Embora de forma não particularizada para nenhum deles, a atenção está voltada para a proposta de uma noção que, a meu ver, poderia contribuir para a articulação dos três elementos fundamentais da 
prática didático-pedagógica: o objeto de ensino, o ensinar e o aprender, envolvendo, respectivamente, conceitos que estão na base dos objetos de ensino, o professor e o aluno. Trata-se da noção de conceito de trabalho ${ }^{4}$, tomada aqui como um instrumento didático equidistante daqueles três elementos básicos, relacionando-se com o objeto de ensino, com o seu ensino e com o modo como esse objeto de ensino se abre para a aprendizagem.

No que se refere ao objeto de ensino e particularizando-o para o campo das linguagens, visa-se propor com os conceitos de trabalho uma alternativa ao modo como que certos conceitos chegam (ou não chegam) ao ensino básico. Refiro-me à como os conceitos chegam em sala de aula, uma vez que os objetos de ensino são, na escola, responsáveis pelo tratamento de conceitos que, estabelecidos pelo conteúdo curricular - currículo elaborado por especialistas, sob a responsabilidade de instâncias governamentais -, são elaborados no campo científico e provenientes de diferentes domínios disciplinares.

No tratamento da linguagem verbal, submeter os conceitos à descorporificação corresponde, por exemplo, a considerar o(s) letramento(s) como limitados ao domínio estrito do sistema alfabético. Do mesmo modo, em outro plano, é tomar a palavra e os aspectos formais ligados a ela como a única fonte de sentido, exclusividade formal que é negada pelas teorias que consideram o plano pragmático da linguagem como ponto de partida para a produção do sentido. A ênfase na pura forma configura um procedimento de esquiva da complexidade do objeto a ser ensinado, pois ele nunca é somente linguístico. Portanto, o objeto de ensino, que é uma terceira voz no diálogo entre o professor e o aluno é fundamental, constituindo uma porta de entrada para o ensino e a aprendizagem.

Intimamente ligado a esse primeiro elemento da prática didático-pedagógica, está o recurso a certos instrumentos didáticos por parte do professor em sua atividade de ensino. Uma vez mais, a proposta de conceitos de trabalho visa evitar certas práticas didáticas. Por exemplo, no caso da produção do texto (oral ou escrito), a pior prática (e, talvez, a mais comum) é, ainda hoje, a do adestramento. Nem sempre explicitada, mas muito disseminada, caberia à escola, segundo essa prática, adestrar os alunos na produção de estruturas formais, fazendo-o pela estrita utilização de modelos. Embora a prática seja antiga, sua sobrevida parece estar garantida pelos instrumentos didáticos utilizados, cujas mudanças no tempo não chegam a alterar significativamente o modo de concebê-los. Em vez da preocupação em como concebê-los, duas preocupações parecem ainda ocupar o lugar central na elaboração desses instrumentos: a da descorporificação do objeto de ensino (por exemplo, o texto visto apenas como um arcabouço formal) e a da descorporificação do próprio instrumento didático (por exemplo, o do uso de modelos fixos). Portanto, a questão do ensino, que - resguardada a sua especificidade - está intimamente ligada à da aprendizagem, é também fundamental.

Justamente a esse respeito é que a noção de conceito de trabalho se aproxima à de instrumento didático. No entanto, a importância dessa noção está no fato de evitar que o instrumento didático se esvazie e ocupe, ele próprio, o lugar do conteúdo curricular e dos objetos de ensino. Os conceitos de trabalho são, portanto, instrumentos didáticos que não se esgotam em sua função instrumental. São, pelo contrário, modos de a vida entrar no que se ensina, o que entendo como viabilização de conceitos com corpo, em oposição às práticas mais comuns de repetição irrefletida de noções e de procedimentos automatizados (por exemplo, na produção escrita). Um outro dado importante é que, no contexto didáticopedagógico, os conceitos de trabalho são um lugar apropriado para desencadear o trabalho

\footnotetext{
${ }^{4}$ Retomando a noção de conceitos de trabalho, lançada por Street (2009, p. 1), assumo, em trabalho anterior (CORRÊA, 2013), que os conceitos de trabalho são instrumentos didáticos aplicados à produção escrita e forjados a partir da perspectiva etnográfico-discursiva. Eles podem ser "formulados a partir de qualquer das dimensões da linguagem com a finalidade de oferecer aos alunos elementos para reflexão e intervenção na sua própria escrita. Eles visam a abrir possibilidades de os alunos se moverem no trânsito entre diferentes práticas escritas, facultando-lhes a entrada para aquelas que eles ainda desconhecem" (CORRÊA, 2013, p. 482).
} 
transdisciplinar (cf. adiante). Mais ainda numa abordagem em que o(s) letramento(s) e sua complexa combinação sejam considerados em sua multiplicidade (nas diferentes práticas), mas também em sua heterogeneidade (na constituição de uma mesma prática, num mesmo sujeito e em um mesmo texto).

No que se refere à aprendizagem, penso que a porta de entrada representada pelos objetos de ensino se fecha sempre que eles são submetidos ao efeito de descorporificação dos conceitos ou quando os instrumentos didáticos tomam o lugar dos objetos de ensino, ocasião em que, ao aluno, cabe apenas repetir.

Essa segunda parte do trabalho está organizada em quatro subtemas, nos quais, primeiramente, justifico duas aproximações: a) a dos campos disciplinares da Medicina Legal e da Linguística Aplicada, e b) a das condições de imputabilidade à condição de letrado. Além disso, procuro refletir sobre: c) como evitar o esvaziamento conceitual na escola; e d) a relação dos conceitos de trabalho com os três elementos fundamentais da relação didáticopedagógica.

Nas considerações finais, faço um apanhado das discussões realizadas no trabalho.

\section{TECNOLOGIA, CORPO E CONTROLE}

$\mathrm{Na}$ história da medicina legal do final do século XIX ao século XX, tal como contada por Courtine e Vigarello (2009), os métodos de identificação do criminoso parecem obedecer a uma tendência de abstração crescente. Essa tendência constante é matizada por dois critérios dominantes: o primeiro critério marca um primeiro momento em que predomina a associação entre comportamento social desviante e anatomia ("Antropologia Criminal") e, o segundo critério marca um segundo momento em que já não há mais o predomínio da associação necessária entre comportamento social e corpo. Um dado novo que baliza e fortalece a refutação da associação entre comportamento social e anatomia na história da imputabilidade criminal é o menor grau de precisão da imagem figurativa (fotografia e retrato falado, utilizados como parte da caracterização antropométrica) quando comparado à precisão da imagem abstrata (a das impressões digitais, propostas pela datiloscopia). Vale destacar, porém, que, no tocante aos efeitos desse desenvolvimento, ao maior grau de abstração dos métodos de identificação, corresponde um maior grau de controle do cidadão por parte da burocracia. $\mathrm{Na}$ execução de suas atividades públicas e em função do controle burocrático de seus papéis, a tendência é que os corpos acumulem o estatuto de imputáveis ao de controlados, condição em que perdem densidade e passam a mover-se segundo uma ordem burocrática, a cujas funções obedecem, mas cujo funcionamento desconhecem.

Ressalte-se, ainda, o papel da tecnologia nesse processo de identificação dos corpos: "a identidade individual se destaca progressivamente da imagem concreta e dos indícios superficiais do corpo para mergulhar nas profundezas abstratas da codificação biológica do organismo" (COURTINE; VIGARELLO, 2009, p. 358). O dado tecnológico vai se impondo de modo a decifrar pela utilização do laser, no final do século XX, o que seriam impressões latentes, "permitindo aos novos peritos do crime colher, com uma precisão inigualável, simples esboços de impressões latentes (COURTINE; VIGARELLO, 2009, p. 358-359). Por fim, o $\mathrm{ADN}^{5}$ forneceria o código genético para estabelecer o "crime como herança", abrindo espaço para o risco de, indevidamente, se correlacionar raça a criminalidade.

Para concluir, ainda em relação ao controle, há que se considerar o aspecto da privacidade. O esvaziamento do corpo de sua densidade histórica - quando a imputabilidade do homem comum passa a ser controle e invasão de sua vida privada - marca "o desenvolvimento dos projetos de identificação biométrica, que visam controlar a

\footnotetext{
${ }^{5}$ Ácido desoxirribonucleico (DNA, em inglês).
} 
"modernidade líquida", os fluxos constantes das pessoas e dos grupos", suscitando "problemas sérios de proteção à privacidade das pessoas e de defesa das liberdades individuais" (COURTINE; VIGARELLO, 2009, p. 360-361).

\section{LETRAMENTO(S) E CONCEITOS DE TRABALHO NO ENSINO E NA APRENDIZAGEM}

\subsection{JUSTIFICATIVA PRÉVIA: DA MEDICINA LEGAL PARA A LINGUÍSTICA APLICADA}

A tendência crescente de abstração nos métodos da Medicina legal está ligada, naturalmente, ao desenvolvimento de recursos tecnológicos e científicos, mas também, quanto aos seus efeitos, a um modo de governar e de conceber o corpo. Pode-se, por exemplo, prescindir da consideração de determinações sociais e históricas quando se aborda o corpo do ponto de vista do código genético (embora seja este sempre ligado àquelas). Isto porque a história coletiva que passa a interessar, nesse caso, é a que está voltada para a configuração abstrata do próprio código genético.

Em termos de linguagem - e penso na Linguística Aplicada - só a fixação em faculdades humanas gerais poderia levar a esses níveis de abstração. Para quem se ocupa da realização pragmática da linguagem, toda forma linguística é investida do social e do histórico. A fixação da identidade no código genético expõe, portanto, duas epistemes opostas: a que privilegia, no individuo, o ser biológico (sua identidade biológica) e a que integra o ser biológico a determinações de ordem "externa", como o fazem, embora não unanimemente, as ciências da linguagem.

Para exemplicar com um conceito advindo destas últimas, tomo o conceito de texto, problematizando a sua gênese estritamente linguística. Mais do que seu aspecto linguístico formal, o que dá corpo ao texto é o fato de ele se investir das práticas sociais em que ocorre. Do mesmo modo, o corpo do indivíduo, quando visto como um texto, só pode ser compreendido e interpretado quando se leva em conta que a expressão facial, as características físicas do conjunto do corpo e as suas representações figurativas e abstratas são signos que falam sobre pertencimentos sociais e que narram uma história. Texto corporificado pelo social e pelo histórico, por um lado, e corpo humano visto como um texto pleno de sentido, por outro, exemplificam uma episteme que prima pela constituição do interior do sujeito pelo que lhe é exterior, investido que é ele das práticas sociais de que participa.

No entanto, quando se trata de constituição de objetos de ensino, do próprio ensino e da aprendizagem, os conceitos das ciências da linguagem correm sempre o risco de ser descorporificados, isto é: (a) quando transformados em objetos de ensino, podem ser reduzidos à sua configuração formal estrita; (b) quando mobilizados por certos instrumentos didáticos no ensino, podem ser reduzidos a modelos estritos sugeridos pelo professor; (c) quando são assim apresentados ao aluno, podem, por fim, ser reduzidos à automatização e à pura repetição.

Neste sentido, o que se produziu no campo da Medicina legal tem correspondência com esse risco no campo da Linguística aplicada, já que, em ambas, a necessária vinculação com a vida concreta e as implicações explicativas requeridas por essa vinculação são as mesmas e podem resultar em controle e repetição. Além dessa aproximação, há uma outra, institucional, ligada à condição disciplinar da Medicina legal e da Linguística Aplicada, ambas com vocação para constituir seus objetos de pesquisa em colaboração com disciplinas vizinhas, ganhando caráter aplicado no sentido de não se desvincularem da vida concreta na sociedade. Portanto, também do ponto de vista institucional, as duas disciplinas guardam algo em comum, o que justifica a aproximação que proponho neste trabalho. 


\title{
2.2 DO CRIMINOSO À CONDIÇÃO DE ILETRADO
}

Retomo, aqui, a noção de letramento mais divulgada no Brasil, pensando, em particular, no acesso direto ou indireto à escrita. Procuro, com essa breve retomada, dirigir a atenção, em particular, para a marginalização social que o problema crônico da alfabetização no Brasil acarreta. A vida cidadã e o gozo de plenos direitos dependem não só de o indivíduo não estar dentre os criminosos, mas também, em certa medida, de ele não estar alheio à condição de letrado.

Para ilustrar, retomo o caso relatado a partir de duas notícias de jornal por Magda Soares (2001, p. 50-54) sobre candidaturas a cargos de prefeito e vereador em um município do interior de São Paulo. Na ocasião, "baseado numa lei que 'proíbe analfabetos de serem candidatos a cargos eletivos", o juiz submeteu candidatos a prefeito e a vereador a um "teste de alfabetização". No primeiro julgamento foi impugnada uma parte significativa (duas ou três dezenas) do conjunto de oitenta candidatos submetidos ao teste. Nesse primeiro momento, foram utilizados critérios mais próximos da noção de letramento: "o candidato deveria: ler e interpretar um texto; redigir um texto sobre o texto lido". Num segundo momento, o Tribunal Regional Eleitoral (TRE) alterou a sentença, liberando a candidatura da parte reprovada no primeiro teste. Para isso, o TRE partiu de critério mais próximo à noção de alfabetização, formulado segundo a definição de alfabetização do dicionário Aurélio: "analfabeto: que não conhece o alfabeto, que não sabe ler e escrever". A justificativa foi a de que os candidatos que tinham sido reprovados não eram analfabetos, pois "tinham "rudimentos da alfabetização"'. Observe-se que as duas decisões obedecem a um mesmo regime, que priva o analfabeto de cidadania - outro modo de referir ao indivíduo descorporificado.

Importa lembrar, ainda, que o analfabeto continua inelegível no Brasil, e que só passou a ter o direito de votar, em caráter facultativo, com a Emenda Constitucional $\mathrm{n}^{\mathrm{o}} 25$, de 15 de maio de $1985^{6}$, facultatividade institucionalizada na Constituição de 1988. É importante ter presente como o voto do analfabeto foi visto no Brasil até a década de 1980, segundo o site do Tribunal Superior Eleitoral (cf. nota 6):

\begin{abstract}
A história do voto no Brasil é uma história de luta de vários segmentos sociais para serem incluídos neste direito, que é o cerne da própria cidadania. [...] Durante o Brasil colônia, havia o voto, segundo as ordenações do Reino, quando uma pessoa ouvia os que não sabiam escrever. Era o chamado voto "cochichado". Do século XVI até o início do século XIX, o voto dos analfabetos sofreu algumas restrições em determinadas ocasiões, mas foi, de certa maneira, preservado. Começa o Império, e o analfabeto ainda vota. Oito anos antes da instituição da República no Brasil, os analfabetos perderam o direito de votar e de participar da vida política do país. A Lei Saraiva (Decreto $\mathrm{n}^{\circ} 3.029$, de 9 de janeiro de 1881) retirou dos analfabetos a possibilidade de voto, ao estabelecer o chamado "censo literário", proposto por Rui Barbosa, que exigiu do eleitor o saber ler e escrever corretamente. A lei criou, pela primeira vez, o 'título de eleitor', impediu o voto dos analfabetos e adotou eleições diretas para todos os cargos eletivos do Império. (STE, 2013).
\end{abstract}

Um indivíduo que não tenha acesso à leitura e à escrita pode, portanto, ser alijado de determinadas esferas, seja por impedimento jurídico, seja por mecanismos de exclusão ligados a relações de poder. A imputabilidade do incapaz pode, portanto, levar a situações tão graves de esvaziamento e controle dos corpos de indivíduos históricos quanto as de imputabilidade criminal. Isso pode ocorrer, p. ex., quando a incapacidade é sustentada por noções vagas como

\footnotetext{
${ }^{6}$ Cf. Supremo Tribunal Eleitoral: Série Inclusão: a luta dos analfabetos para garantir seu direito ao voto na República, 15/04/2013. Disponível em: http://www.tse.jus.br/imprensa/noticias-tse/2013/Abril/serie-inclusao-aluta-dos-analfabetos-para-garantir-seu-direito-ao-voto-na-republica . Acesso em 12 abr. 2019.
} 
a de ignorância, doença mental, imaturidade e quando é atribuída, ao sabor das conveniências, a corpos que falham (quais não?) e passam a ser considerados não plenos.

\title{
2.3 EVITAR O ESVAZIAMENTO CONCEITUAL: LETRAMENTO, TRANSDISCIPLINARIDADE E CONCEITO DE TRABALHO
}

\subsubsection{LETRAMENTO E CONCEITO DE TRABALHO}

Street, ao considerar os conhecimentos, técnicas e normas de comportamento de um dado povo - características, dentre outras, caras à Antropologia Cultural - busca uma perspectiva transcultural de estudo, em que a complexidade dos conhecimentos locais é fortemente considerada no contato com outras configurações culturais.

Essa perspectiva transcultural contém uma proposta epistemológica bastante inovadora. A investigação de uma cultura local requer, segundo essa visão, uma mudança de posto de observação - o exercício de ocupação do lugar do outro -, de tal modo que o estudo de uma cultura local tenha como efeito iluminar o conhecimento do que o autor chama de cultura colonial (externa à sociedade estudada) ou de cultura dominante (interna à sociedade estudada).

A mesma posição epistemológica parece estar presente em Bonvini, quando o pesquisador fala das civilizações africanas. É o que procuro apreender de suas aulas quando penso a relação entre culturas com e sem escrita:

\begin{abstract}
a expressão civilização da oralidade - utilizada pelo historiador e africanista Emilio Bonvini em curso ministrado na Universidade de São Paulo, em 2008, para substituir tradição oral -, dá um novo alcance às práticas orais. Segundo Bonvini, por meio dessa expressão, deseja-se ultrapassar o nível superficial (local) para se chegar ao nível mais profundo. Ou seja, falar de civilização, de maneira de ser e de existir no mundo é falar do que há de comum a muitas realidades, a realidades supranacionais, fato que permite enfrentar, de modo positivo, essa maneira de existir - conclui o autor. (CORRÊA, 2008, p. 77).
\end{abstract}

Nesse contexto, o(s) letramento(s) dominantes em sala de aula deveriam ser dois: o escolar, orientado por determinações curriculares embasadas em correntes teóricas específicas, tal como a dos multiletramentos, e o extraescolar, presentificado pela heterogeneidade de letramentos que informam sobre as práticas sociais pelas quais o aluno circula, sem esquecer que o próprio professor é marcado por especificidades de sua circulação social. Além disso, para lidar com um tipo de letramento em toda a sua amplitude, não basta fixar-se apenas no aspecto físico da tecnologia que compõe a sua materialidade sígnica, contra o que o contraexemplo mais claro é o do erro clássico de se pensar a escrita apenas por seu aspecto gráfico, sua base semiótica ${ }^{7}$.

No confronto entre dois tipos de letramentos, o trabalho de extraposição do professor é o que daria autoria à sua prática didática, marcada pelo letramento escolar, mas sem desconsiderar o letramento extraescolar do aluno e a desejável visada crítica também sobre o seu próprio. Considerada, portanto, a assunção do posto de observação do outro, tal como sugerido por Street e, a meu ver, corroborado por Bonvini, utilizo-me desse gesto epistemológico para propor a noção de conceito de trabalho, já tematizada anteriormente. Os conceitos de trabalho impõem, por um lado, assumir o papel do aluno como central, ponto de chegada dos objetos de ensino. Nesse sentido, o sintagma "de trabalho" em "conceitos de trabalho" se referiria à extraposição do professor em relação à posição do aluno para fazer

\footnotetext{
${ }^{7}$ Não podendo me estender sobre esta questão, remeto o leitor a trabalho anterior. Cf. a respeito da base semiótica da escrita, Corrêa (1997, p. 50-65).
} 
chegar a este último um objeto de ensino. Por outro lado, essa mudança do posto de observação do professor depende do fato de ele não abandonar o seu próprio posto, ou seja, não abandonar aquilo que é intrínseco ao trabalho do professor: seu alcance didático e pedagógico propriamente ditos, dirigidos à sua ação na sociedade. Note-se que, em se transferindo a sugestão de Street para o campo pedagógico, procura-se garantir, com a noção de conceito de trabalho e a consequente extraposição do professor, o efetivo encontro entre aluno e professor.

\subsubsection{TRANSDISCIPLINARIDADE E CONCEITO DE TRABALHO}

Espero que até este ponto tenha ficado claro que a importância da noção de conceito de trabalho está em evitar: a) que os objetos de ensino sejam privados da história que sempre os constitui (evitar a sua descorporificação); e b) que o instrumento didático não ocupe, ele próprio, o lugar do conteúdo curricular e dos objetos de ensino. Os conceitos de trabalho são, como ficou dito, instrumentos didáticos que não se esgotam em sua função instrumental, constituindo-se, pelo contrário, em modos de a vida entrar no que se ensina, em oposição às práticas mais comuns de repetição irrefletida de noções e de procedimentos automatizados.

Outro modo de formular essa ideia envolve um segundo gesto epistemológico. Da mesma forma que ao tratar do(s) letramento(s) em sala de aula, se espera que o professor ocupe o posto de observação do aluno (gesto epistemológico, pois implica tomar contato com outro modo de conhecer), o segundo gesto consiste do fato de que, no contexto didáticopedagógico, os conceitos de trabalho são o lugar apropriado para desencadear o trabalho transdisciplinar.

No campo aplicado, os conhecimentos das ciências da linguagem estão sempre em contato com conhecimentos produzidos em disciplinas vizinhas (a etnografia, mas também a sociologia, a história e as ciências da educação). Nesse sentido, defendo que o ensino das manifestações do(s) letramento(s) só tem a ganhar com uma concepção de conceitos de trabalho cuja elaboração se baseie numa visada transdisciplinar (SIGNORINI; CAVALCANTI, 1998; LEFFA, 2006a; 2006b; SCHEIFER, 2013).

A propósito, o procedimento adotado neste trabalho é um exemplo de visada transdisciplinar. Ao tomar como ponto de partida a oposição entre corpo pleno e a ideia de descorporificação para fazer referência ao corpo sem densidade, sem vida, sem o estofo de suas determinações sociais e históricas procuro formular, na verdade, um instrumento de reflexão que suponho ter permitido passar da abordagem do corpo do indivíduo histórico pela Medicina legal para o campo de uma outra disciplina, a Linguística Aplicada, ao lembrar o risco de se trabalhar, nesta última, com conceitos vagos, também descorporificados, desprovidos de sua densidade social e histórica. Por mais distante que a associação possa parecer, os efeitos da descorporificação dos conceitos na escola são muito próximos, se não os mesmos, do sujeito controlado a que o desenvolvimento das técnicas de identificação do criminoso levou. Num caso e noutro é do controle da vida dos indivíduos que se trata.

Essa possibilidade aberta à relação entre disciplinas, buscando estar atento, não propriamente à reprodução disciplinada das regulações disciplinares ${ }^{8}$, mas ao objeto de reflexão construído é, a meu ver, o cerne do trabalho transdisciplinar. Não é, portanto, a defesa dos corpos disciplinares que interessa, mas o trabalho com a relação entre disciplinas o que se poderia definir como um trabalho com o incorpóreo dessa relação, lugar da gênese dos objetos de reflexão, de seu acontecimento. Ainda que o presente artigo não corresponda a uma ilustração do que propõe Signorini (1998), a ideia de acontecimento está no horizonte da reflexão porque se liga, particularmente, ao processo discursivo, que inclui continuidades e

\footnotetext{
${ }^{8}$ Faço alusão ao título do livro organizado por Moita Lopes (2006): Por uma Linguística Aplicada Indisciplinar.
} 
descontinuidades. Como afirma a autora:

a principal implicação epistemológica de um deslocamento desse tipo é, pois, o rompimento com cadeias conceituais e expectativas teleológicas e totalizantes, em favor de uma sistematicidade tão rigorosa - ou tão 'científica' - quanto possível, mas aberta e orientada para o acontecimento, [...], os processos em andamento. (SIGNORINI, 1998, p. 103).

Não se trata, aqui, de uma proposta de ruptura com a Linguística nem com qualquer outra disciplina, mas de uma visão que já situa o linguístico no cruzamento transdisciplinar com a sociologia e com a história, concebendo-o como parte do processo discursivo. Desse modo, no exercício transdisciplinar levado a efeito no presente trabalho, a perspectiva que orienta toda a reflexão - a perspectiva etnográfico-discursiva - já nasce como transdisciplinar, pois o que está em jogo não são as disciplinas isoladamente, mas os objetos que nascem da relação entre elas. Portanto, em termos da produção de conhecimento não é a constituição de um novo campo disciplinar distinto da Linguística que está em questão, mas de outro modo de lidar com o conhecimento. Não se trata, tampouco, apenas de uma mera intervenção teóricometodológica, mas também de uma intervenção epistemológica.

É, pois, também como fruto do trabalho transdisciplinar que o(s) letramento(s) e sua complexa combinação são considerados em sua multiplicidade (nas diferentes práticas), mas também em sua heterogeneidade (na constituição de uma mesma prática, num mesmo sujeito e em um mesmo texto). Desse modo, ao lado da descrição etnográfica extensiva das práticas sociais e do(s) letramento(s) a elas ligados, cabe observar também sua combinação intensiva em objetos conceituais particulares, o que tenho optado por fazer a partir de uma visão discursiva. Novamente, duas disciplinas em relação e o objeto de reflexão (o efeito de heterogeneidade) obtido como o acontecimento da relação entre elas.

A novidade, no entanto, não está tão-somente no trabalho transdisciplinar, mas no fato de que os conceitos de trabalho, concebidos como unidades de conhecimento repostas no curso da vida, são portas abertas para o trabalho transdisciplinar ${ }^{9}$ em sala de aula. Essa ideia é essencial tanto para a compreensão do(s) letramento(s), quanto para o ensino e a aprendizagem de suas manifestações, incluindo a produção e a leitura do texto (escrito, falado ou verbo-visual). Pensar o(s) letramento(s) como formas de contato com diferentes práticas sociais, ou seja, como modos de a vida entrar no que se ensina, é pensar também na constituição dos conceitos de trabalho, lugar ótimo para o trabalho transdisciplinar. Note-se que, no percurso de constituição de um conceito de trabalho, a direção do tratamento transdisciplinar vai do objeto de pesquisa (no caso em questão, dos conceitos de trabalho) para as diferentes contribuições disciplinares (para contribuições teóricas afins) ${ }^{10}$.

A título de considerações finais e para dar fechamento a este trabalho, apresento o papel dos conceitos de trabalho em relação a cada um dos três elementos fundamentais da relação didático-pedagógica: o objeto de ensino, o ensinar e o aprender.

\subsection{EFEITOS DOS CONCEITOS DE TRABALHO NA PRÁTICA DIDÁTICO-PEDAGÓGICA}

Os conceitos de trabalho são, como ficou dito, um instrumento didático equidistante daqueles três elementos básicos, relacionando-se, portanto, com o objeto de ensino, com o seu ensino e com o modo como esse objeto de ensino se abre para a aprendizagem. A título de

\footnotetext{
${ }^{9}$ Como mostra Scheifer (2013), são muito diversos os tratamentos que o trabalho transdisciplinar tem tido, inclusive no Brasil. Destaco além de Scheifer (2013), também os trabalhos de Celani; de Kleiman e de Signorini todos publicados em 1998, como parte do livro organizado por Signorini; Cavalcanti (1998), e também os Leffa (2006a; 2006b) e de Moita Lopes (2006).

${ }^{10}$ Neste sentido, talvez me aproxime do que propõe Leffa (2006a) ao tratar dos objetos de aprendizagem.
} 
fechamento desta reflexão, destaco o papel dos conceitos de trabalho quanto aos três elementos básicos da comunicação, propostos aqui em termos da prática didático-pedagógica.

\subsubsection{CONCEITOS DE TRABALHO E SUA RELAÇÃO COM OBJETOS DE ENSINO E INSTRUMENTOS DIDÁTICOS}

A noção de letramento (no plural) assumida neste trabalho, ao dar lugar à ideia de multiplicidade, considera também a sua heterogeneidade na constituição das práticas sociais, dos sujeitos e dos textos. Considerar que as práticas sociais se cruzam e se interpenetram é também considerar que o(s) letramento(s) se combinam, já que, como elas, são constituídos da mesma matéria social e histórica. Como procurei mostrar, a matéria social e histórica pode ser reconhecida tanto nos indivíduos (como mostram os efeitos do desenvolvimento das formas de identificação do imputável pela Medicina legal) quanto nos conceitos (como procuro mostrar no campo da educação). Ou seja, na condição de tipos de saberes ligados a diferentes práticas sociais, $\mathrm{o}(\mathrm{s})$ letramento(s), sendo intercambiáveis segundo formas, tecnologias e regulações socioculturais e históricas, habitam os corpos dos indivíduos - caso da condição de letrado -, mas também podem ser flagrados nos conceitos e nos instrumentos didáticos que procuram tornar cognoscíveis os conceitos levados para a sala de aula.

Tendo presente, porém, que a constituição histórica dos conceitos pode ser apagada, isto é, que sua matéria constitutiva pode ser esvaziada ou mitigada, cabe refletir sobre os objetos de ensino e os instrumentos didáticos.

Os conceitos, que estão na base dos objetos de ensino, e os instrumentos didáticos podem ser esvaziados de sua constituição histórica em favor, por exemplo, de sua redução à sua configuração formal, a seu suporte ou à tecnologia, os quais fazem circular os conceitos e os instrumentos didáticos. O resultado é uma formulação espectral dos objetos de ensino e dos conceitos que os fundamentam, a qual simula vagamente, mas contribui para apagar, seu vínculo com a vida. Produz-se, como efeito, uma relação com o objeto de ensino que gira em falso em torno de um ponto zero de sentido, como exemplificam os casos: a) da ênfase exclusiva no domínio do sistema alfabético (produzindo incapacidade para leitura e escrita de textos elementares); b) da produção textual baseada unicamente em arcabouços formais reprodutíveis (produzindo textos sem coerência suficientemente clara para produzir sentido autônomo); c) do ensino de categorias gramaticais sem atenção à produção de sentido etc. Neste último caso, pode-se pensar no trabalho com uma categoria como a preposição, caracterizando-a apenas como pertencente ao conjunto dos itens lexicais estritamente gramaticais, sem vinculação com o mundo biossocial - o que, apesar de ser, em parte, verdadeiro, levaria a perder o seu peso etimológico e, sobretudo, o seu caráter relacional e a semântica das relações que cada preposição estabelece no enunciado, acarretando a perda de sua vinculação com os sujeitos e com o mundo. Se isso pode ocorrer quanto à noção de preposição, também o instrumento didático pode inviabilizar qualquer chance de vinculação desse conceito com o mundo. É o caso de se adotar como instrumento didático a simples memorização da famosa lista das preposições por muito tempo decorada pelos alunos: "a, ante, após, até, com, como, conforme, contra, de, desde, durante,...”. Embora se possa pensar que essa prática já não seja mais constatável nas escolas, valeria considerar que também os recursos de esvaziamento dos conceitos se renovam.

\subsubsection{Sobre ensinar e aprender: as figuras do professor e do aluno e o objeto de ensino}

Ao discutir o corpo sob controle ficou assentado que um corpo controlado (sem densidade, descorporificado) tem relação com o papel dos indivíduos na burocracia, em que, 
ao conhecimento de suas funções, equivale o desconhecimento do próprio funcionamento burocrático.

A escola é um espaço especialmente sensível às normas e ao controle, e o controle dos corpos caminha passo a passo com o controle burocrático, que se instala de modo privilegiado na escola. Nela, os movimentos são rigorosamente controlados e se apoiam em instrumentos de controle, como o relógio, os sinais de entrada/saída, a vigilância (pessoal ou por câmeras); os procedimentos de chegada/saída de alunos, sem contar as limitações impostas aos comportamentos de professores e alunos. Nesse espaço, em que o controle é exacerbado, a vida entra e sai a murros. Os problemas de adaptação, os casos de alunos com dificuldades específicas, os comportamentos impróprios ligados a problemas familiares, a desestruturação familiar como ruído no aproveitamento dos alunos são alguns dos modos como a vida grita - mas não dialoga - na escola.

No tocante ao tema do(s) letramento(s) e pensando no corpo controlado no campo pedagógico, trata-se, por um lado, do próprio modo de ensinar a aprender e, por outro, de ser capaz de discriminar o modo ótimo de ser ensinado. Como fazer, afinal?

O caminho apontado para a abordagem da noção de letramento(s) foi explorar a sua complexidade para dar corpo a conceitos de trabalho. Não se furtar à complexidade é o diferencial para se contrapor à facilitação repetidora. Privilegiar a complexidade significa, portanto, conter, em alguma medida, o controle estabelecido na eleição/elaboração - em geral feita de cima para baixo na hierarquia da escola - e na concepção dos objetos de ensino, suscetíveis às expectativas de pais, mantenedores (seja o setor público ou privado) e à visão nada edificadora sobre educação que orienta muitas escolas. Significa, por fim, partir de uma noção de conceito de trabalho que, como espaço de transdisciplinaridade, permita que os objetos de ensino assegurem uma dimensão pedagógica mais ampla do que simplesmente a de integrar a rotina automatizada do ensino.

Longe de se fixar nos conceitos de trabalho como entidades cuja essência devesse ser buscada, é a sua abertura ao trabalho transdisciplinar que deve ser destacada. Onde, portanto, se poderia buscar, ontologicamente, uma entidade essencial a ser transposta para o ensino, encontra-se, ao contrário, o cruzamento de perspectivas de disciplinas afins ao campo da linguagem e, no caso em questão, às teorias do(s) letramento(s), o que garante que se ofereça o objeto de ensino por um ângulo determinado, mas de modo multireferenciado. Diante de conceitos de trabalho que não oferecem uma essência a ser buscada ou memorizada pelo aluno, mas estimulam a discussão e o confronto de perspectivas, tanto o fazer didáticopedagógico quanto a aprendizagem decorrentes dessa escolha metodológica se alinham a novos modos de conhecer, consolidando, portanto, uma contribuição que é, em sua base, epistemológica.

\section{CONSIDERAÇÕES FINAIS}

$\mathrm{Na}$ escola ou na vida, a descorporificação (dos indivíduos históricos ou dos conceitos) está ligada a mecanismos de controle. No tripé fundamental das relações didáticopedagógicas, a relação professor/aluno depende sempre da relação de cada um deles com o objeto de ensino (e, por meio deste, com conceitos que marcam a presença do conteúdo curricular e de conhecimentos disciplinares do campo científico na sala de aula). Por sua vez, essa terceira voz que dialoga com o professor e o aluno demanda não uma simples audiência, mas o trabalho com um modo de conhecer que pode ser elaborado na própria sala de aula. A proposta de conceitos de trabalho que sejam equidistantes dos três elementos dessa relação, prevê: a) objetos de ensino que jamais apresentem conceitos descorporificados (isto é, que fujam à complexidade de sua constituição na sociedade e na história); b) professor aberto a utilizar esses conceitos de trabalho como instrumentos didáticos voltados sempre à reflexão (e 
não à estrita exposição de modelos); c) alunos estimulados a produzir conhecimento (e não simplesmente a repetir mecânica e indefinidamente o que lhe é fornecido). Nesse contexto, a sala de aula é espaço de produção (e não de simples transmissão) de conhecimento, e os conceitos de trabalho são, ao mesmo tempo, instrumentos didáticos (voltados para o ensino, na qualidade de agentes de aprendizagem) e expediente de descoberta (voltados à produção de conhecimento, na qualidade de agentes de aprendizagem ativa), ou seja, o objeto de ensino, centro de atenção na elaboração de conceitos de trabalho, não pode ser estabelecido ontologicamente a não ser pelas múltiplas relações que ele abre no momento de sua realização no ensino. Como expedientes de descoberta, os conceitos de trabalho se apresentam como lugar ótimo para o exercício da transdisciplinaridade, ponto de encontro entre disciplinas em torno de um objeto sobre o qual se deposita um interesse pontual.

Ao lidarem com conteúdos de ensino como o do(s) letramento(s), esse modo de produzir conhecimento se sustenta desde que o(s) letramento(s) sejam tomados como compósitos de língua, cultura, sociedade e história, que não se descrevem simplesmente como idênticos à tecnologia com que atuam numa determinada prática social. Não correspondendo ao dado mais aparente de sua realização (seu suporte ou o recurso tecnológico que o apresenta), o(s) letramento(s) têm de ser buscados na opacidade das práticas sociais, as quais incluem aquele compósito que nutre o corpo dos conceitos e situam - na polêmica - o lugar de encontro entre as disciplinas e do acontecimento dos objetos de ensino a pesquisar.

\section{Referências}

BAKHTIN, M. Estética da criação verbal. Tradução de Maria Ermantina Galvão G. Pereira. São Paulo: Martins Fontes, 1992.

CALliARI, M. Zumbis com celulares nas mãos. Jornal O Estado de São Paulo, São Paulo, 18 jun. 2017. Disponível em: https://sao-paulo.estadao.com.br/blogs/caminhadas-urbanas/zumbisZumbiscom-celulares-nas-maos/. Acesso em: 02 abr. 2019.

CELANI, M. A. A. Transdisciplinaridade na Linguística Aplicada no Brasil. In: CELANI, M.A.A. Linguística Aplicada e transdisciplinaridade: questões e perspectivas. Campinas: Mercado de Letras, 1998. p. 129-142.

CORRÊA, M. L. G. O modo heterogêneo de constituição da escrita. 1997. 422f. Tese (doutorado) Universidade Estadual de Campinas, Instituto de Estudos da Linguagem, Campinas, SP. Disponível em: http://www.repositorio.unicamp.br/handle/REPOSIP/270919. Acesso em: 21 abr. 2019.

CORREAA, M. L. G. Arranjos referenciais de tempo em textos de pré-universitários: letramento e oralidade. Gragoatá, Niterói, n. 25, p. 75-93, $2^{\circ}$ sem. 2008. Disponível em: http://www.gragoata.uff.br/index.php/gragoata/article/view/231 . Acesso em: 12 abr. 2019.

CORREAA, M. L. G. As perspectivas etnográfica e discursiva no ensino da escrita: o exemplo de textos de pré-universitários. Revista da ABRALIN, [s.1.], v. 10, n. 4, p. 333-356 , 2011. Disponível em: https://revistas.ufpr.br/abralin/article/view/32435. Acesso em 09 abr. 2019.

CORRÊA, M. L. G. Bases teóricas para o ensino da escrita. Linguagem em (Dis)curso, Tubarão, SC, v. 13, p. 481-513, set./dez. 2013. Disponível em: http://www.scielo.br/pdf/ld/v13n3/03.pdf . Acesso em: 05 abr. 2019.

COURTINE, J-J. e VIGARELLO, G. Identificar - traços, indícios, suspeitas. In: COURTINE, J-J.; VIGARELLO, G; CORBIN. História do corpo: as mutações do olhar : o século XX. Trad. e rev. Ephraim Ferreira Alves, 3. ed., Petrópolis, RJ : Vozes, 2009. p. 341-361. 
FOUCAULT, M. O pensamento do exterior. São Paulo: Princípio, 1990.

FOUCAULT, M. Vigiar e punir: nascimento da prisão. Trad. Raquel Ramalhete. 20ed. Petrópolis: Vozes, 1999.

KLEIMAN, A. O estatuto disciplinar da Linguística Aplicada: o traçado de um percurso, um rumo para o debate. In: SIGNORINI, I.; CAVALCANTI, M. C. (Org.). Linguística aplicada e transdisciplinaridade: questões e perspectivas. Campinas: Mercado de Letras, 1998. p. 51-77.

KOCH, I. V. O texto e a construção dos sentidos. São Paulo: Contexto, 1998.

LEFFA, V. J. Nem tudo que balança cai: objetos de aprendizagem no ensino de línguas. Polifonia. Cuiabá, v. 12, n. 2, p. 15-45, 2006a. Disponível em: http://periodicoscientificos.ufmt.br/ojs/index.php/polifonia/article/view/1069/841 . Acesso em: 19 abr. 2019.

LEFFA, V. J. Transdisciplinaridade no ensino de línguas: A perspectiva das Teorias da Complexidade. Revista Brasileira de Linguística Aplicada, Belo Horizonte, v. 6, n. 1, p. 27-49, 2006b. Disponível em: http://www.scielo.br/scielo.php?script=sci arttext\&pid=S198463982017000100113\&lng=en\&nrm=iso . Acesso em: 21 abr. 2019.

MOITA LOPES, L. P. Linguística aplicada e vida contemporânea: problematização dos construtos que têm orientado a pesquisa. In: MOITA LOPES, L. P. (Org.). Por uma linguística aplicada INdisciplinar. São Paulo: Parábola Editorial, 2006. p. 85-107.

MOITA LOPES, L. P. (Org) Por uma linguística aplicada indisciplinar. São Paulo : Parábola, 2006.

ONG. W. Oralidade e cultura escrita: a tecnologização da palavra. Campinas, SP: Papirus, 1998.

SCHEIFER, C. L. Transdisciplinaridade na linguística aplicada: um processo de desreterritorialização - um movimento do terceiro espaço. Revista Brasileira de Linguística Aplicada, Belo Horizonte, v. 13, n. 3, p. 919-939, 2013. https://www.academia.edu/4749414/Transdisciplinaridade_na_Lingu\%C3\%ADstica_Aplicada_Um_p rocesso de desreterritorialização _- Um movimento do terceiro espaço . Acesso em: 15 abr. 2019.

SIGNORINI, I. Do residual ao múltiplo e ao complexo: o objeto de pesquisa em Linguística Aplicada. In: SIGNORINI, I.; CAVALCANTI, M. P. (Org.). Linguística aplicada e transdisciplinaridade: questões e perspectivas. Campinas: Mercado de Letras, p. 99-110, 1998.

SIGNORINI, I; CAVALCANTI, M. P. (Org.) Linguística aplicada e transdisciplinaridade: questões e perspectivas. Campinas: Mercado de Letras, 1998.

SOARES, M. Letramento: um tema em três gêneros. São Paulo: Autêntica, 2001.

STREET, B. V. "Hidden" features of academic paper writing. Working Papers in Educational Linguistics, Philadelphia, v. 24, n. 1, p. 01-17, 2009. Disponível em: https://repository.upenn.edu/cgi/viewcontent.cgi?article=1203\&context=wpel. Acesso em: 05 abr. 2019.

STREET, B. V. Letramentos sociais: abordagens críticas do letramento no desenvolvimento, na etnografia e na educação. Trad. Marcos Bagno. São Paulo: Parábola, 2014.

VOLOSHINOV, V. N. / BAKHTIN, M. M. Discurso na vida e discurso na arte (sobre poética sociológica). Trad.: Carlos Alberto Faraco e Cristovão Tezza [para uso didático, com base na tradução inglesa do original de 1926, feita por I. R. Titunik e publicada em: Voloshinov. Freudism. New York, 
Academic Press, 1976. s.d.]

Manoel Luiz Gonçalves Corrêa

mcorrea@usp.br

Recebido em:

Aceito em:

Publicado em: 